MIDAS

Museus e estudos interdisciplinares

$12 \mid 2020$

Varia

\title{
Laboratório de Artes na Montanha - Graça Morais: um projeto em construção
}

Laboratory Arts in the Mountain - Graça Morais: a bridge between the local and the global

\section{António Meireles e Joana Baião}

\section{OpenEdition}

\section{Journals}

Edição electrónica

URL: https://journals.openedition.org/midas/2478

DOI: $10.4000 /$ midas. 2478

ISSN: $2182-9543$

Editora:

Alice Semedo, Paulo Simões Rodrigues, Pedro Casaleiro, Raquel Henriques da Silva, Ana Carvalho

\section{Refêrencia eletrónica}

António Meireles e Joana Baião, «Laboratório de Artes na Montanha - Graça Morais: um projeto em construção», MIDAS [Online], 12 | 2020, posto online no dia 15 dezembro 2020, consultado no dia 05 março 2022. URL: http://journals.openedition.org/midas/2478 ; DOI: https://doi.org/10.4000/midas. 2478

Este documento foi criado de forma automática no dia 5 março 2022

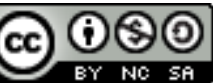

Midas is licensed under a Creative Commons Attribution-NonCommercial-ShareAlike 3.0 International License 


\title{
Laboratório de Artes na Montanha - Graça Morais: um projeto em construção
}

Laboratory Arts in the Mountain - Graça Morais: a bridge between the local and the global

\author{
António Meireles e Joana Baião
}

\section{NOTA DO EDITOR}

Artigo recebido a 04.10.2019

Aprovado para publicação a 19.07.2020

\section{Introdução'}

Atualmente, temos acesso a uma quantidade de informação antes inimaginável e a meios que permitem que um qualquer acontecimento seja partilhado imediatamente pelo mundo, fazendo com que o tempo e o espaço não limitem a comunicação, antes sendo parte ativa para que tudo esteja disponível no imediato. Os aspetos essenciais da aldeia global que Marshall McLuhan e Bruce R. Powers (1992) idealizaram na década de 1960 têm-se tornado norma na sociedade atual. Esta aldeia global, sobretudo mediada digitalmente, permite que tenhamos referências culturais e artísticas mundiais, ligando de algum modo o que é global e o que é local. Esta não é, no entanto, uma relação totalmente recíproca, pois o mundo local das nossas vivências não encontra igual eco de propagação. Tal verifica-se no emprego e partilha de referências remotas, e na modesta presença - seja em tempo como em espaço significativo - do que é circunscrito a territórios específicos. 
2 Ciente de que a cultura e a arte são meios fundamentais de conhecimento, consciencialização e valorização da identidade de povos em territórios singulares, em particular no território de Montanha que caracteriza a região de Bragança, o Instituto Politécnico de Bragança estabeleceu um conjunto de parcerias para a constituição do Laboratório de Artes na Montanha - Graça Morais. Este projeto visa estabelecer conexões entre a cultura, a arte e a ciência, mobilizando e articulando atividades formativas, criações artísticas, processos de documentação, o desenvolvimento de investigação e a disseminação de resultados. Mais do que combater uma aldeia global na promoção do mundo local, pretende-se com este laboratório estabelecer diálogos construtivos que melhor permitam potenciar as suas caraterísticas constitutivas para a reflexão, construção e expressão crítica e criativa da sociedade.

\section{Cultura e arte em terras de Trás-os-Montes}

3 O contexto da região em que Bragança se inscreve é muito particular. É o espaço continental mais distante de Lisboa, com o que tal compreende na deslocação de bens e pessoas, mesmo em tempos de desmaterialização crescente.

4 Em termos administrativos o território organiza-se desde 2013 na Comunidade Intermunicipal das Terras de Trás-os-Montes, que compreende quatro cidades (Bragança, Macedo de Cavaleiros, Miranda do Douro, Mirandela), nove vilas e 533 aldeias, com uma população total de 117.527 residentes. ${ }^{2}$ As povoações são dispersas e, regra geral, de pequena dimensão, mercê de uma demografia progressivamente reduzida e envelhecida, e da elevada mobilidade para as grandes cidades do litoral e para o estrangeiro. A região é predominantemente rural, sendo os terrenos agrícolas pequenos e fragmentados, persistindo a agricultura tradicional e a pastorícia (Sousa 2013).

5 A região transmontana reveste-se de um enorme atrativo pelas suas características paisagísticas, naturais e humanas, suscetíveis de serem enformadas naqueles elementos que definem, distinguem e são valiosos neste território: a cultura, o património e a arte. A cultura é um pilar estrutural da identidade de uma região, congregando a história e a tradição dos povos no que têm de mais característico e identitário. Neste, como noutros territórios, a cultura é o ligante de aspetos físicos e sociais, associando com fluidez anseios, esperanças, medos, hábitos, orografia ou meteorologia, entre outros. Mais do que estar ligada a características materiais de um espaço (embora seja delas subsidiária), cabe à cultura a definição de um território identitário e dos modos de ligação a outros territórios, com maior ou menor proximidade física, por estar ligada às pessoas e às suas atividades.

6 Com a consciência da importância que a cultura tem, e com a sua evidenciação não só enquanto valor em si, mas enquanto elemento estrutural complexo capaz de gerar mais valor, esta tem vindo, cada vez mais, a constituir uma área de importante investimento público, tanto em termos globais como no que se refere à despesa corrente e de capital. No caso específico das Terras de Trás-os-Montes, esse investimento tem-se refletido na criação crescente de novos museus, centros de arte e galerias de exposições (v. tabela n. - 1), bem como de bibliotecas, teatros ou outras instalações culturais. Estes equipamentos, cuja tutela é sobretudo municipal, permitem o cumprimento de funções de musealização, exposição e divulgação de conteúdos, tanto de origem própria, como exterior. 
Tabela n. ${ }^{\circ} 1$ - Museu, galerias de arte e outros espaços de exposição temporária

\begin{tabular}{|c|c|c|c|}
\hline \multicolumn{4}{|c|}{$\begin{array}{l}\text { Comunidade Intermunicipal das Terras de Trás-os-Montes - Museus, Galerias de Arte e } \\
\text { outros espaços de exposição temporária }\end{array}$} \\
\hline & 2001 & 2010 & 2019 \\
\hline Terras de Trás-os-Montes & 9 & 21 & 32 \\
\hline Alfândega da Fé & 1 & 1 & 2 \\
\hline Bragança & 1 & 8 & 11 \\
\hline Macedo de Cavaleiros & 1 & 3 & 6 \\
\hline Miranda do Douro & 3 & 3 & 6 \\
\hline Mirandela & 2 & 1 & 2 \\
\hline Mogadouro & 0 & 1 & 4 \\
\hline Vila Flor & 0 & 2 & 2 \\
\hline Vimioso & 1 & 1 & 0 \\
\hline Vinhais & 0 & 1 & 1 \\
\hline
\end{tabular}

Fonte: PORDATA ${ }^{3}$

7 A cultura que o nordeste transmontano gerou desde tempos imemoriais, e que se tem conseguido preservar, nomeadamente através destes equipamentos, permite o estabelecimento de pontes entre espaços e tempos diversos, unindo o passado, a contemporaneidade e o futuro, não apenas no seu seio como, e sobretudo, com outros territórios. Neste âmbito, a cultura identitária transmontana funda-se nos vestígios do passado, sendo elementos cruciais desse legado cultural, quer os testemunhos materiais (móveis e imóveis) presentes ou recolhidos na região, quer os testemunhos de tradições, usos e costumes, práticas e atividades ancestrais, que constituem o seu rico património tangível e intangível.

8 Para além disso, destaca-se como valor cultural ativo a produção intelectual e artística produzida diretamente ligada à região, como por exemplo os estudos arqueológicos e etnográficos desenvolvidos por Francisco Manuel Alves (1865-1947), mais conhecido por Abade de Baçal, fundamentais para a compreensão da história e cultura transmontanas; o universo literário de Miguel Torga (pseudónimo de Adolfo Correia da Rocha, 1907-1995), marcado pelas referências às serras, aos ciclos da natureza e ao universo do trabalho rural característico deste território; ou a pintura de Graça Morais (n. 1948), que apesar de universal, é fruto e testemunho do seu contacto com as gentes e tradições locais. Destacamos, de seguida, esta última referência. 


\section{A obra de Graça Morais - breve caracterização}

9 Graça Morais nasceu na pequena aldeia do Vieiro e de lá partiu para o mundo. Encontrando o que no mundo é comum ao Vieiro, trabalhou também o que lhe é distinto e, no que é a prorrogativa da arte e da ciência, descobriu e criou novos mundos. A sua obra, resultante de mais de 40 anos de ininterrupta atividade, estabelece uma relação que une o local ao global, num movimento recíproco e numa dinâmica que envolve o observador e, principalmente, o questiona.

10 O trabalho de Graça Morais caracteriza-se pela permanente observação do ser humano e da sua condição no mundo. Num plano mais próximo ao das suas vivências e contacto com o mundo rural, destacam-se, desde logo, os registos que testemunham os ciclos e as várias práticas relacionadas com a vida da aldeia, a íntima relação entre o homem e a natureza, as vivências da comunidade: a fauna e a flora da montanha, a caça, a agricultura e as colheitas, as matanças do porco, as procissões, entre outras (Ferreira 1985). Simultaneamente, a sua obra caracteriza-se pela abordagem desassombrada ao universo feminino: as mulheres que habitam os seus quadros, embora aparentemente simples e passivas, representam uma força motriz ancestral que trabalha, é geradora de vida e é perpetuadora de saberes, garantindo a vitalidade do mundo (Costa 2014, 72-74). Embora grande parte do seu universo pictórico remeta para o contexto das suas memórias e experiências no território transmontano, são inúmeros os trabalhos concebidos noutras geografias, em contacto com comunidades e culturas diversificadas. Refiram-se, a título de exemplo, as séries de trabalhos decorrentes de estadias prolongadas em Cabo Verde (1988-1989) ou em Sines (2005). Por outro lado, a sensibilidade da pintora não se esgota nas questões relacionadas com o género ou com as representações de usos, práticas, ritos e costumes ligados a uma territorialidade pessoal. Temas mais abrangentes e universais como a religião, o sexo, o envelhecimento, a solidão, o exílio ou a guerra habitam o seu universo plástico e refletem o seu olhar atento sobre tudo o que a rodeia, desde a aldeia aos países mais distantes (v. AAVV 2017; AAVV 2019).

\section{O Laboratório de Artes na Montanha - Graça Morais}

11 A área de montanha a que Bragança pertence configura uma identidade geográfica e social que se tem constituído como polo de investigação específico, designadamente através do Instituto Politécnico de Bragança (IPB), com as suas várias escolas e centros de investigação ${ }^{4}$, potenciando, à semelhança da obra da pintora Graça Morais, a ligação entre o que é específico ao território e o que configura um mundo global, numa ação que articula a arte e a ciência.

Consciente dos desafios relacionados com as interações dinâmicas entre local e global, entre centralidade e descentralização cultural e científica, e com as potencialidades de investigação e difusão de conhecimento proporcionadas pela articulação entre arte e ciência, o IPB - que desde 1983 cumpre a missão da formação e da investigação que caraterizam o ensino superior politécnico com uma necessária ligação à comunidade criou em 2018 o Laboratório de Artes na Montanha - Graça Morais (LAM-GM).

13 A constituição do LAM-GM foi impulsionada pelo Ministro da Ciência, Tecnologia e Ensino Superior, Manuel Heitor, que estimulou o contacto entre as várias entidades que 
viriam a integrar formalmente o projeto ${ }^{5}$ : IPB, através do Centro de Investigação de Montanha (CIMO) e da Escola Superior de Educação (ESE); o Centro de Arte Contemporânea Graça Morais (CACGM), através da sua tutela, a Câmara Municipal de Bragança (CMB); o Instituto de História da Arte da Universidade Nova de Lisboa (IHA, FCSH/NOVA); e a Fundação para a Ciência e Tecnologia (FCT). ${ }^{6}$ Também a pintora Graça Morais colabora ativamente no LAM-GM, disponibilizando o acesso à sua obra e à documentação correlativa para estudo, catalogação e divulgação.

14 A base de atuação do projeto do LAM-GM decorre da articulação funcional entre dois parceiros com missões e natureza diferentes, mas com campos de ação complementares, o IPB e o CACGM. O IPB compreende uma oferta formativa de cursos de âmbito artístico, com uma importante componente de estudo e intervenção na comunidade e no território onde está implantado, bem como a atividade de prática e investigação artística dos seus docentes. Paralelamente, o CACGM (criado em 2008) tem promovido uma atividade expositiva que coloca a obra da pintora Graça Morais em diálogo com a produção de vários artistas contemporâneos, tanto nacionais, como internacionais. ${ }^{7}$ Deste modo, o LAM-GM surge como resposta a necessidades verificadas na concretização de práticas artísticas, decorrentes de processos de formação específica no campo das artes, bem como de necessidades mais globais de formação de públicos.

150 trabalho que até ao momento tem vindo a ser desenvolvido pelos diferentes intervenientes, com toda a valia que tem merecido justo reconhecimento, tem mostrado a premência de uma estrutura centralizada que permita articular e otimizar recursos, ações e projetos, ganhando eficácia e escala. Tal estrutura permite encarar de modo especializado e integrando projetos de financiamento de ações e investigações no campo artístico, possibilitando uma investigação sistemática da obra da pintora Graça Morais, bem como da produção artística do contexto de montanha, e potenciando simultaneamente o diálogo entre os vários agentes (academia, instituições culturais, empresas), a criação de emprego científico, a atividade formativa, a criação artística e a disseminação de resultados. Neste domínio da promoção de práticas de investigação integradas e integradoras, tanto na sua conceção, como no seu desenvolvimento e divulgação, refira-se a candidatura bem-sucedida do seed project "Intervenções de Arte Pública: Da Catalogação ao Museu Virtual - Study-case Graça Morais", a financiamento disponibilizado pelo Instituto de História da Arte da FCSH/NOVA. Assumindo como base de trabalho o corpus de obra pública de Graça Morais, este micro-projeto tem como enfoque os desafios conceptuais e práticos contemporâneos relacionados com a catalogação e documentação de arte pública ou intervenções artísticas em espaços arquitetónicos, e a sua comunicação ao público através de ferramentas digitais. ${ }^{8}$

O LAM-GM estabelece-se como estrutura que permite desenvolver um trabalho em rede, rentabilizando o papel de cada um dos seus intervenientes, e explorando a excecional localização geográfica brigantina enquanto plataforma de contacto interregional e transfronteiriça - de facto, o afastamento relativo de Lisboa configura a aproximação relativa à Europa e em particular, a Espanha. Simultaneamente, este projeto aspira à promoção de um percurso inverso, de valorização do que é local e específico, não no sentido de o tornar global, mas procurando estabelecer um diálogo construtivo entre estas duas dimensões. Assim, pretende-se intervir na comunidade local, procurando valorar o território e as comunidades tanto locais como regionais, através do ponto de vista artístico e social, gerando e promovendo criadores, fruidores e pensadores artísticos, e procurando dotar com ferramentas básicas de intervenção e 
análise as comunidades envolvidas. Neste sentido, existem quatro grupos de destinatários do laboratório: as comunidades de implantação local e regional, funcionando o LAM-GM como plataforma de contacto formativo específico, à imagem dos Centros de Ciência Viva; a comunidade artística, enquanto geradora de ações e produtos mediante a prática intensiva e a investigação dedicada, como são o desenvolvimento de residências artísticas ou os cursos de verão; e as comunidades académicas e museológicas, locais, nacionais e internacionais - com clara valorização dos contactos transfronteiriços -, mediante a formalização e a divulgação da prática e investigação artística desenvolvidas e a incorporação destas nos processos formativos em curso e numa comunidade mais ampla, contemplando a expansão internacional da obra da pintora Graça Morais.

\section{Considerações finais}

17 O LAM-GM tem como principal propósito promover a articulação entre a investigação científica, a formação académica e a criação e divulgação artísticas numa rede nacional e transfronteiriça de parcerias. Um breve balanço dos seus dois primeiros anos de atividade coloca já em evidência o cumprimento dos seus objetivos e a sua orientação para o futuro.

18 No campo da investigação, destacam-se os trabalhos em torno da inventariação sistemática de estudos, desenhos, pinturas e outros trabalhos da pintora Graça Morais, com vista à elaboração do seu Catálogo Raisonné e a criação de um Centro de Documentação, bem como a participação em projetos de investigação como o "Programa Verão com Ciência 2020", que contribuem para ensaiar e implementar novos processos de investigação através da arte. ${ }^{9}$

19 No âmbito da formação académica, são de realçar a adaptação de Planos de Estudos e Unidades Curriculares dos cursos artísticos do IPB, com vista ao desenvolvimento de novas metodologias pedagógicas e formativas baseadas na prática artística, assim como a criação de uma Unidade Curricular dedicada ao estudo da obra da pintora Graça Morais, passível de ser frequentada por qualquer estudante do IPB, tanto de planos de estudos regulares como de mobilidade, ou a integração em programas colaborativos, como é exemplo a plataforma Demola. ${ }^{10}$

20 No campo da disseminação e contacto com públicos variados, merecem realce os projetos desenvolvidos em estreita parceria com o CACGM, como por exemplo a preparação da acessibilidade a públicos com necessidades especiais às exposições promovidas por aquela instituição, ou a promoção conjunta de atividades de formação de públicos a partir daquele espaço e/ou das obras expostas.

21 Como laboratório que é, o LAM-GM propõe uma ação balizada pela experimentação e pela construção de saber partilhados entre os elementos envolvidos na estrutura, as comunidades locais e regionais de implantação e desenvolvimento de projetos e ações, e os destinatários últimos, que podendo ser oriundos de contextos geográficos diferenciados, desenvolvem uma ação no contexto específico de implantação desta nova estrutura.

22 Conceptualmente o LAM-GM não se encontra veiculado a programas estéticos ou científicos pré-definidos, pautando a sua ação pelo rigor, excelência e criatividade dos processos desenvolvidos e produtos obtidos. Assim, considera-se que toda a prática e 
investigação artística compreendem pela sua natureza uma criação, ou seja, o desenvolvimento de algo novo, antes não existente ou considerado. Esta criação não é niilista, abrangendo e valorizando o que a antecede, mas promovendo necessariamente valores de originalidade e de criatividade.

Estando localizado numa região com um importante património cultural, o LAM-GM não tem como função uma mera continuidade deste património, mas antes a sua exploração, como recurso que também é, para uma criação geradora de valor. Pretende-se que a sua estrutura seja simples, eficaz e uma ferramenta útil para o desenvolvimento de uma ação criadora em vários níveis.

Em conclusão, iniciando as suas atividades com pequenos e seguros passos num desenvolvimento sustentado, promissor e agregador, o Laboratório de Artes na Montanha - Graça Morais visa estabelecer pontes entre realidades locais e globais através da cultura, da arte e da ciência. Possa o caráter seminal em potência da construção de conhecimento ser o sustentáculo do desenvolvimento de múltiplas ações, formações, criações, reflexões e sua divulgação, gerando criadores e, mais genericamente, cidadãos críticos, conscientes e criativos. Possa o território ser a génese de uma reflexão e ação culturais e artísticas que, em articulação com referências globais, consiga potenciar o seu desenvolvimento integrado e integrador.

\section{BIBLIOGRAFIA}

AAVV. 2017. Graça Morais. La Violence et la Grâce. Paris: Somogy Éditions d'art.

AAVV. 2018. Centro de Arte Contemporânea Graça Morais - 10 Anos, 2008-2018. Bragança: Município de Bragança.

AAVV. 2019. Graça Morais, 10 Anos. Centro de Arte Contemporânea Graça Morais 2008-2018. Bragança: Centro de Arte Contemporânea Graça Morais e Município de Bragança.

AAVV. 2019. Metamorfoses da Humanidade. Lisboa: Guerra \& Paz Editores.

AAVV. 2020. In2CoP 2020 - Conferência Internacional em Processos de Cocriação no Ensino Superior 2020: Livro de Resumos. Bragança: Instituto Politécnico de Bragança.

Costa, Jorge da. 2014. Graça Morais. Territórios da Memória. Porto: Universidade Católica Editora.

McLuhan, Marshall e Bruce R. Powers. 1992. The Global Village: Transformations in World life and Media in the 21st Century. Oxford: Oxford University Press.

Mega Ferreira, António. 1985. Graça Morais. Linhas da Terra. Lisboa: Imprensa Nacional-Casa da Moeda.

Meireles, António e Joana Baião. 2019. "Laboratório de Artes na Montanha - Graça Morais. Uma Ponte entre o Mundo Local e a Aldeia Global." In Arte e Cultura na Identidade dos Povos. XXIX Encontro da Associação das Universidades de Língua Portuguesa, coord. Cristina Montalvão Sarmento, Pandora Guimarães e Patrícia Oliveira, 117-122. Lisboa: AULP. 
Sousa, Fernando de, coord. 2013. Bragança na Época Contemporânea (1820-2012). Bragança: Câmara Municipal de Bragança.

\section{NOTAS}

1. Este breve artigo foi adaptado a partir de uma comunicação apresentada no XXIX Encontro da AULP (Associação das Universidades de Língua Portuguesa) que se realizou no Instituto Politécnico de Lisboa nos dias 3-5 de julho de 2019 (v. Meireles e Baião 2019, 117-122).

2. Dados relativos aos Censos 2011. Fonte: Comunidade Intermunicipal Terras de Trás-os-Montes, https://www.cim-ttm.pt/pages/485 (consultado em dezembro 17, 2020).

3. https://www.pordata.pt/Tema/Municipios/Cultura-47 (consultado em dezembro 17, 2020).

4. O IPB integra: Escola Superior de Educação; Escola Superior Agrária; Escola Superior de Tecnologia e Gestão; Escola Superior de Comunicação; Administração e Turismo; e Escola Superior de Saúde. É de destacar, no último quadro de Avaliação das Unidades de I\&D no âmbito do Programa Plurianual de Financiamento, a atribuição da nota Excelente a dois dos seus cinco centros de investigação: Centro de Investigação de Montanha (CIMO) e Centro de Investigação em Digitalização e Robótica Inteligente (CeDRI).

5. A formalização do projeto decorreu em julho de 2018, com a assinatura do protocolo de colaboração entre estas entidades. A assinatura do protocolo coincidiu com a comemoração do 10.aniversário do Centro de Arte Contemporânea Graça Morais, em Bragança.

6. Financiamento "Protocolo estabelecido com a Fundação para a Ciência e a Tecnologia, e no âmbito da Resolução do Conselho de Ministros n. 116/2018 (medida n.o 5.18)", Ref. UI/ 00690/2020.

7. São testemunhos desta intensa e variada atividade os dois catálogos editados por ocasião do 10. aniversário do CACGM, que elencam todas as exposições nele produzidas: AAVV (2018) e AAVV (2019).

8. https://institutodehistoriadaarte.wordpress.com/2020/10/12/iha-seed-project-intervencoesde-arte-publica/ (consultado em dezembro 17, 2020).

9. O Estágio de iniciação científica - Residência Artística - Artes na Montanha realizado no âmbito do Apoio Especial Verão com Ciência 2020 configurou um programa de investigação inovador nas áreas de artes Plásticas, design e comunicação audiovisual, educação artística, literatura e multimédia, envolvendo 18 bolseiros e 8 supervisores no que foi uma proposta única no panorama nacional: https://www.fct.pt/apoios/veraocomciencia/docs/Acoes_Selecionadas.pdf (consultado em dezembro 17, 2020).

10. Plataforma de cocriação que interrelaciona empresas, instituições de ensino superior e organizações públicas, para desafios de inovação. Alguns resultados da integração do LAM-GM e do CACGM nesta plataforma foram apresentados no encontro In2CoP 2020 - Conferência Internacional em Processos de Cocriação no Ensino Superior (v. AAVV 2020, 21-24).

\section{RESUMOS}

A pintora portuguesa Graça Morais (n. 1948) partiu de uma pequena aldeia transmontana, o Vieiro, para o mundo e encontrando o que no mundo é comum ao Vieiro, trabalhou também o 
que lhe é distinto e, no que é a prorrogativa da arte e da ciência, descobriu e criou novos mundos. A sua obra, resultante de mais de 40 anos de atividade, tem a virtude de estabelecer uma relação que une o local ao global e o global ao local numa dinâmica que envolve o observador e o questiona. Partindo da obra tutelar da pintora Graça Morais, o Instituto Politécnico de Bragança criou em 2018 o Laboratório de Artes na Montanha - Graça Morais, estrutura de investigação resultante de uma parceria estratégica com a Câmara Municipal de Bragança/Centro de Arte Contemporânea Graça Morais, o Instituto de História da Arte da Faculdade de Ciências Sociais e Humanas da Universidade Nova de Lisboa, a Fundação para a Ciência e a Tecnologia, e a própria pintora. Neste breve artigo fazemos o enquadramento deste novo projeto que, unindo arte e ciência, visa potenciar a atividade formativa, promover a criação artística e dinamizar processos de documentação, investigação e disseminação de resultados, contribuindo para tornar Bragança e o território envolvente em novas referências de descentralização científica e cultural e, simultaneamente, uma plataforma de contacto com todo o mundo.

The Portuguese painter Graça Morais (b. 1948) is the author of an extensive work which reflects both her origins - a small rural village in Northeast Portugal - and her experience in a cosmopolitan and constantly changing world. Her paintings not only evoke memories, but also describe contemporary events, thus intersecting the local and the global, the past and the present, in a dynamic approach that involves and questions the observer - and, through him, all humankind. Inspired by the tutelary work of the painter Graça Morais and her continuous activity over the last 40 years, the Instituto Politécnico de Bragança (Polytechnic Institute of Bragança) has recently created the Laboratório de Artes na Montanha - Graça Morais (Laboratory Arts in the Mountain - Graça Morais), a research structure that results from a strategic partnership between the Câmara Municipal de Bragança (Municipality of Bragança)/Centro de Arte Contemporânea Graça Morais (Contemporary Art Centre Graça Morais), the Instituto de História da Arte of the Faculdade de Ciências Sociais e Humanas, Universidade Nova de Lisboa, the Portuguese Foundation for Science and Technology, and the painter herself. In this short article, we present the framework of this project which, promoting and disseminating scientific and artistic research and creation, formative activities and innovative academic training, aiming to convert Bragança and its surroundings in a decentralized hub of cultural events and, at the same time, a contact platform with the whole world.

\section{ÍNDICE}

Palavras-chave: Graça Morais, descentralização cultural, Centro de Arte Contemporânea Graça Morais, projeto de investigação, coleção arte contemporânea

Keywords: Graça Morais, cultural decentralization, Contemporary Art Centre Graça Morais, research project, contemporary art collection

\section{AUTORES}

\section{ANTÓNIO MEIRELES}

Doutor em Belas Artes, especialidade em Desenho (2015), pela Faculdade de Belas-Artes da Universidade de Lisboa, mestre em Desenho (2005) e licenciado em Artes Plásticas - Pintura. É também detentor do título de Especialista em Belas-Artes atribuído pelo consórcio dos Institutos Politécnicos de Bragança, Lisboa, Coimbra e Viana do Castelo (2012). É docente do departamento de Artes Visuais na Escola Superior de Educação do Instituto Politécnico de Bragança desde 2002. 
Escola Superior de Educação do Instituto Politécnico de Bragança, Campus de Santa Apolónia, 5300-253 Bragança, Portugal, antoniomeireles@ipb.pt

\section{JOANA BAIÃO}

Doutora em História da Arte - especialização em Museologia e Património Artístico (2014) e mestre em Museologia pela Faculdade de Ciências Sociais e Humanas da Universidade Nova de Lisboa (2009). Licenciada em Escultura pela Faculdade de Belas-Artes da Universidade de Lisboa (2005). Foi bolseira de pós-doutoramento da Fundação para a Ciência e a Tecnologia entre 2016 e 2019. Membro integrado do Instituto de História da Arte da Faculdade de Ciências Sociais e Humanas da Universidade Nova e investigadora do Centro de Investigação de Montanha (CIMO), Instituto Politécnico de Bragança, no âmbito do Laboratório de Artes na Montanha - Graça Morais.

Escola Superior de Educação do Instituto Politécnico de Bragança, Campus de Santa Apolónia, 5300-253 Bragança, Portugal, jbaiao@ipb.pt 